Int. J. Dev. Biol. 56: 819-831 (2012)

doi: $10.1387 / \mathrm{ijdb} .120133 \mathrm{cc}$

\title{
The antral follicle: a microenvironment for oocyte differentiation
}

\author{
MARGO L. HENNET and CATHERINE M.H. COMBELLES* \\ Middlebury College, Biology Department, Middlebury, VT, USA
}

\begin{abstract}
Mammalian reproduction hinges upon the timely ovulation of a fully differentiated oocyte. This event is the culmination of a complex and dynamic developmental relationship between the oocyte and the antral follicle housing it; the antral follicle constitutes a specialized microenvironment or niche, uniquely suited to the needs of the oocyte as it approaches ovulation. During this time, the oocyte must complete its final growth, capacitation, and nuclear and cytoplasmic maturation. Its microenvironment-the antral follicle-is in turn responsible for the integrity of these processes and the production of a high quality oocyte. Components of the antral follicle, including three distinct somatic cell types (theca, granulosa and cumulus), the basal lamina, and follicular fluid, each have active and regulatory roles in oocyte differentiation. Several milestones in antral folliculogenesis also have an influence on oocyte development. This review will discuss the antral follicle microenvironment with specific attention to its importance in oocyte differentiation. As assisted reproductive technologies (ART) often require stages of oocyte differentiation to occur in vitro rather than in vivo, current knowledge of the antral follicle microenvironment will also be discussed with respect to its clinical applications.
\end{abstract}

KEY WORDS: antral follicle, oocyte, microenvironment, niche, oocyte quality

\section{Introduction}

Mammalian reproduction is a sheltered and highly specialized process. Although the importance of a microenvironment for reproductive success culminates with fetal development in the uterus, it begins with oocyte growth inside a follicle. The follicle is an ovarian structure that provides for and influences the quality of the oocyte within. Often, however, assisted reproductive technologies (ART) remove the oocyte from its follicular microenvironment and ask it to complete the final stages of its development in vitro. In order to compensate for the absence of a natural milieu, the role of the follicle during final oocyte differentiation must be thoroughly understood. Although many questions remain, significant progress has thus far been made in unravelling this complex system.

The culminating differentiation events of the oocyte-final growth, capacitation, and maturation-occur in the days preceeding and surrounding ovulation. At this time, the follicle is comprised of a fluid-filled chamber, or antrum, and several distinct somatic cell types. Each component of the antral follicle contributes to the microenvironment essential for successful oocyte differentiation and subsequent fertilization. In this review, we will present a current profile of oocyte differentiation inside the pre-ovulatory antral follicle, with specific focus on the microenvironment and its relevancies to ART.

\section{A brief overview of the antral follicle}

Antral follicles are characterized by the presence of an antrum, which is filled with follicular fluid derived both from the bloodstream and from components secreted by somatic cells inside the follicle. It contains a variety of molecules including steroid and protein hormones, anticoagulants, enzymes and electrolytes. This rich fluid bathes the oocyte as it develops and mediates communication between various cell types within the follicle. Two types of granulosa cells, the mural granulosa cells and a specialized cell type called cumulus cells, define the internal structure of the follicle. The cumulus cells surround the oocyte, forming a cumulus-oocyte complex (COC), while the granulosa cells form the inner lining of the follicle. Each follicle is enveloped by a basal lamina, a specialized sheet of extracellular matrix that separates the internal follicle from the third somatic follicular cell type, the

Abbreviations used in this paper: ART, assisted reproductive technology; COC, cumulusoocyte complex; IVM, in vitro maturation; ROS, reactive oxygen species.

\footnotetext{
*Address correspondence to: Catherine Combelles. Middlebury College, Biology Department, McCardell Bicentennial Hall 346 , Middlebury, VT 05753, USA. Tel: +1-802-443-5251. Fax: +1-802-443-2072. e-mail: ccombell@ middlebury.edu
} 
theca cells. Theca cells are a vascularized cell layer that defines the outer boundary of the antral follicle (Fig. 1).

\section{An outline of antral folliculogenesis}

In mammals such as humans and cows, each estrous or menstrual cycle produces a single mature oocyte for ovulation and fertilization. However, the oocyte cannot reach this point of development without the support of its follicle. Folliculogenesis is an intricate process by which one follicle per cycle is selected to develop fully and thereby create a mature oocyte. The latter phase of folliculogenesis is termed antral folliculogenesis, and its progress is entirely dependent on gonadotropic hormones.

Antral folliculogenesis occurs in waves of growth and regression. Circulating levels of follicle stimulating hormone (FSH) support the growth of a group of antral follicles until the largest follicle begins producing estradiol-an FSH suppressor - and transitions to dependence on luteinizing hormone ( $\mathrm{LH}$ ) (in the bovine this occurs when the largest follicle is approximately $8.5 \mathrm{~mm}$ ). This follicle is termed the dominant follicle, and this event is called follicle selection. As FSH levels decline, the rest of the antral follicles will regress in a process called atresia (discussed later) and the dominant follicle will be the only follicle capable of reaching ovulation.

Whether or not a dominant follicle will in fact reach ovulation depends on the frequency and amplitude of LH pulses continually induced in the pituitary. These LH pulses will increase in intensity as more time elapses from the previous cycle's ovulation event (due to luteolysis of the corpus luteum and diminishing progesterone levels), and eventually culminate in a surge sufficient to induce ovulation. However, within a typical estrous or menstrual cycle, the selection of a dominant follicle (following a wave of antral follicle growth) can happen two or three times before LH levels facilitate ovulation. Dominant follicles that do not encounter the LH surge regress through atresia, allowing $\mathrm{FSH}$ levels to rise and support the growth of a new group of antral follicles (reviewed by Scaramuzzi et al., 2011).

Atresia is characterized by cell death within a follicle, and it is the process by which all follicles regress if they do not reach ovulation. The underlying mechanism of this condition is apoptosis, or programmed cell death. An early atretic follicle may have only a handful of dying cells, however, as atresia progresses into its latest stages, the granulosa cell and cumulus cell populations die, followed by resorption of follicular fluid and oocyte death (reviewed by Irving-Rodgers et al., 2001).

\section{The final differentiation events of the oocyte}

Oogenesis encompasses a protracted growth phase followed by capacitation and subsequently an even shorter period of maturation (Fig. 2). Together, these events permit the making of an oocyte that can support the formation and development of an embryo to term. The task is thus grand, and not surprisingly complex and multi-faceted.

The bulk of oocyte growth occurs prior to antral folliculogenesis, yet some final growth still occurs in the early stages of antral folliculogenesis. Indeed, the oocyte continues a small portion of its growth after antral formation, and completes it by the time the antral follicle reaches $3 \mathrm{~mm}$ in size in the bovine (Fair, 2003). Not only do many organelles (e.g. mitochondria, Golgi, cortical granules) accumulate, but they also undergo changes in their distribution and organization (reviewed by (Hyttel et al., 1997). Together, these cytoplasmic modifications enable the oocyte to complete its later

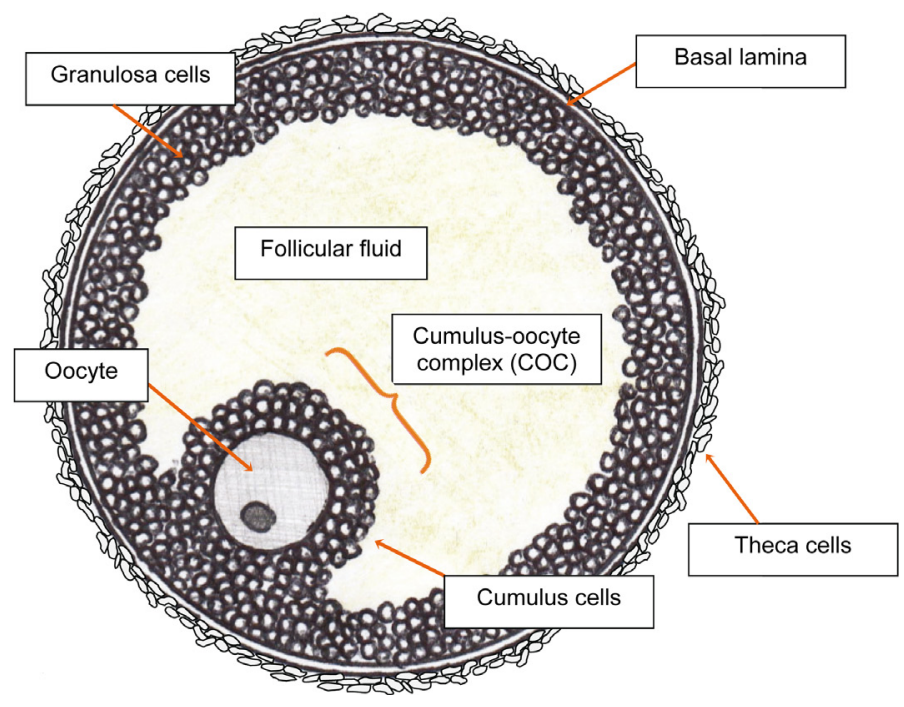

Fig. 1. Schematic representation of an antral follicle.

differentiation program and pursue its fate as a developing embryo. Nuclear changes also take place during oocyte growth. The oocyte is transcriptionally active by the time the antral follicle first forms, and stored transcripts are essential to sustain early embryonic development until genome activation. However, oocyte transcription is not a long-lasting process within the antral follicle, as transcriptional repression and nucleolus inactivity take place during late phases of oocyte growth (Fair et al., 1997). Penultimate oocyte growth is also a time when the imprinting of genes increases (O'Doherty et al., 2012). A fully grown oocyte is able to resume meiosis, and, depending on the species, it will acquire the capacity to complete meiosis shortly thereafter. Regardless of its meiotic competence, an oocyte's developmental competence remains low at this time.

Upon completion of oocyte growth and prior to oocyte maturation, an essential step of pre-maturation, or capacitation, must take place within the confines of the antral follicle. More precisely, capacitation will occur in the oocyte of the selected, dominant follicle as it completes its growth (Hyttel et al., 1997; Fair, 2003). Capacitation is a pre-requisite for the oocyte to acquire complete developmental competence; in fact, the failure to undergo a normal capacitation program may underlie many instances of developmental arrest and/ or compromised embryo quality. The specifics of oocyte capacitation remain undefined. Broadly, it encompasses molecular (with further stockpiling of proteins), as well as structural changes (with reduction in the size of the Golgi, increase in lipid droplets, and relocation of cortical granules) (Hyttel et al., 1997; Dieleman et al., 2002).

The last differentiation event that the developing oocyte will undergo within the antral follicle is oocyte maturation. During maturation, the oocyte progresses from prophase-I through meiosis-I until it arrests at metaphase-II, at which point the oocyte is released from the full-grown dominant follicle. Oocyte maturation occurs in response to the pre-ovulatory LH surge, and it encompasses a complex set of nuclear and cytoplasmic changes, not all of which are yet described. Nuclear events involve meiotic progression (e.g. nuclear envelope breakdown and chromosome condensation), while cytoplasmic maturation refers to all accompanying events that are necessary to support not only normal maturation but also subsequent development. Beyond changes in organelles and 
their distributions (e.g. smooth endoplasmic reticulum and cortical granules), a post-transcriptional control of polyadenylation is critical to the long-term storage and reactivation of mRNA transcripts (Gandolfi and Gandolfi, 2001). Proteins also continue to accumulate during oocyte maturation (Sirard et al., 1989). The exact orchestration of nuclear and cytoplasmic events is another important area of research given reported instances of asynchrony and resulting developmental arrests. While the oocyte is maturing, changes also occur in the surrounding cumulus cells, with cumulus expansion and modifications in the communication conduits between the two cell types (reviewed by Russell and Salustri, 2006).

The oocytes thus experiences preparatory steps (over a protracted and progressive phase) followed by culminating steps in its development, which together permit the differentiation of an oocyte capable of completing development to term (Fig. 2). Overall, the oocyte undergoes a particularly complex program of events while housed in the ever-changing microenvironment of the antral follicle. In the course of its differentiation, the oocyte is influenced by non-cellular and cellular components of the follicular milieu (Fig. $3)$; the nature of some of these influences will be presented next.

\section{Oocyte differentiation: support from components of the antral follicle}

\section{Follicular fluid}

The composition of follicular fluid is distinct from that of serum, suggesting that it may be uniquely tailored to suit the needs of developing oocytes. Although much remains unknown or unclear regarding the complex compositional profile of follicular fluid, we can define several distinct ways in which its various contents influence the penultimate differentiation of the oocyte. This review focuses on three components of follicular fluid that have a significant influence on oocyte differentiation: reactive oxygen species and antioxidants, hormones, and metabolites.

\section{Reactive oxygen species (ROS) and antioxidants}

The balance between reactive oxygen species (ROS) and antioxidants in follicular fluid is critical to the production of a competent oocyte. ROS are unstable and highly reactive oxygen-containing molecules with one or two unpaired electrons in the outer orbit. To become stable, they oxidize or reduce other stable molecules such as nucleic acids, lipids, proteins and carbohydrates, leading to a chain reaction of electron-stealing and the formation of free radicals.

At low levels, ROS are essential for some cell functions and signaling pathways. Indeed, there is some evidence that their presence in follicular fluid may modulate oocyte maturation, meiotic arrest, and meiotic resumption. For instance, blocking or suppressing ROS with antioxidants reversibly inhibited the resumption of meiosis in rat oocytes in vitro (Takami et al., 1999), although the mechanism by which this occurred was not fully investigated. At high levels, however, ROS can cause serious damage to cellular function. Excessive levels of ROS have been shown to cause aberrations to the microtubule organization and chromosomal alignment of metaphase II meiotic spindles in mouse oocytes in vitro (Choi et al., 2007), and to inhibit oocyte maturation in the mouse (Tamura et al., 2008). Other features of the oocyte, such as the fluidity of its plasma membrane (necessary for fusing with sperm at fertilization), are also vulnerable to attack by ROS. There does not appear to be a consensus in the literature regarding the precise concentrations of ROS that are required for "healthy" oogenesis and folliculogenesis.

Maintaining appropriate levels of ROS within the follicular fluid requires the presence of antioxidants - enzymatic and non-enzymatic molecules that neutralize the ROS that they encounter. Interestingly, several studies report that levels of antioxidants in follicular fluid fluctuate with follicle size, suggesting that antioxidants-and by extension ROS - might be produced or maintained in response to the developing needs of the antral follicle and oocyte. For instance, levels of superoxide dismutase (SOD), an enzymatic antioxidant,

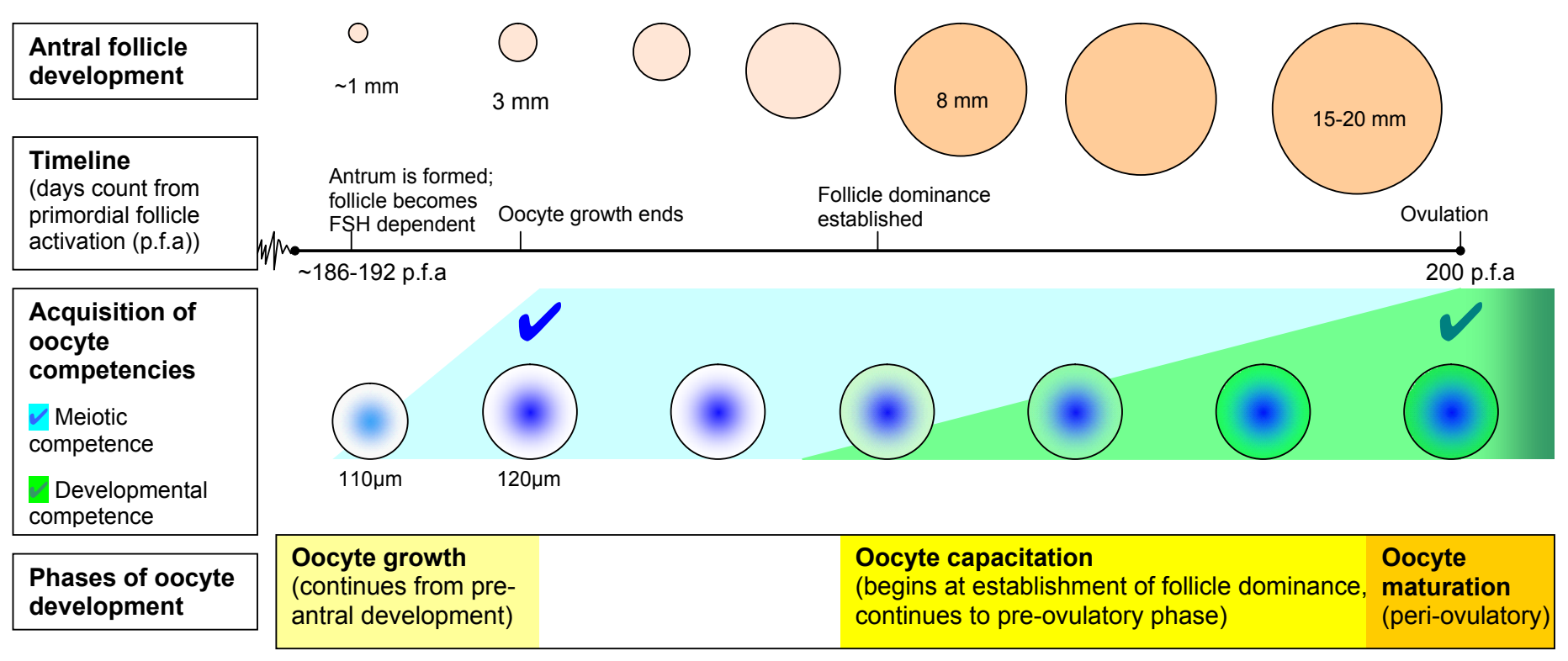

Fig. 2. The acquisition of oocyte competencies, and phases of oocyte development, in relation to antral folliculogenesis in the bovine. Although small differences exist between the human and bovine models, the bovine is currently a more completely characterized model for antral folliculogenesis. Check marks over oocytes indicate full acquisition of competency. 
in bovine follicular fluid decrease with increasing follicle size (Combelles et al., 2010), although total antioxidant capacity (TAC) was reported to be highest in the follicular fluid of larger follicles (Gupta et al., 2011). These trends suggest that the antioxidant/ ROS balance in follicular fluid is actively and specifically adapted as folliculogenesis and oogenesis progress. Other antioxidants in follicular fluid include melatonin, glutathione peroxidases, catalase, and vitamin E (reviewed by Revelli et al., 2009).

\section{Hormones}

Follicular fluid hormone concentrations influence oocyte differentiation both directly (via genomic and non-genomic action) and indirectly (via somatic cells within the follicle). The response of somatic cells within the follicle to intra-follicular concentrations of hormones is a vital part of pre-ovulatory folliculogenesis and oogenesis. The hormones found in follicular fluid include $\mathrm{FSH}$, $\mathrm{LH}$, growth hormone $(\mathrm{GH})$, human chorionic gonadotropin (hCG),

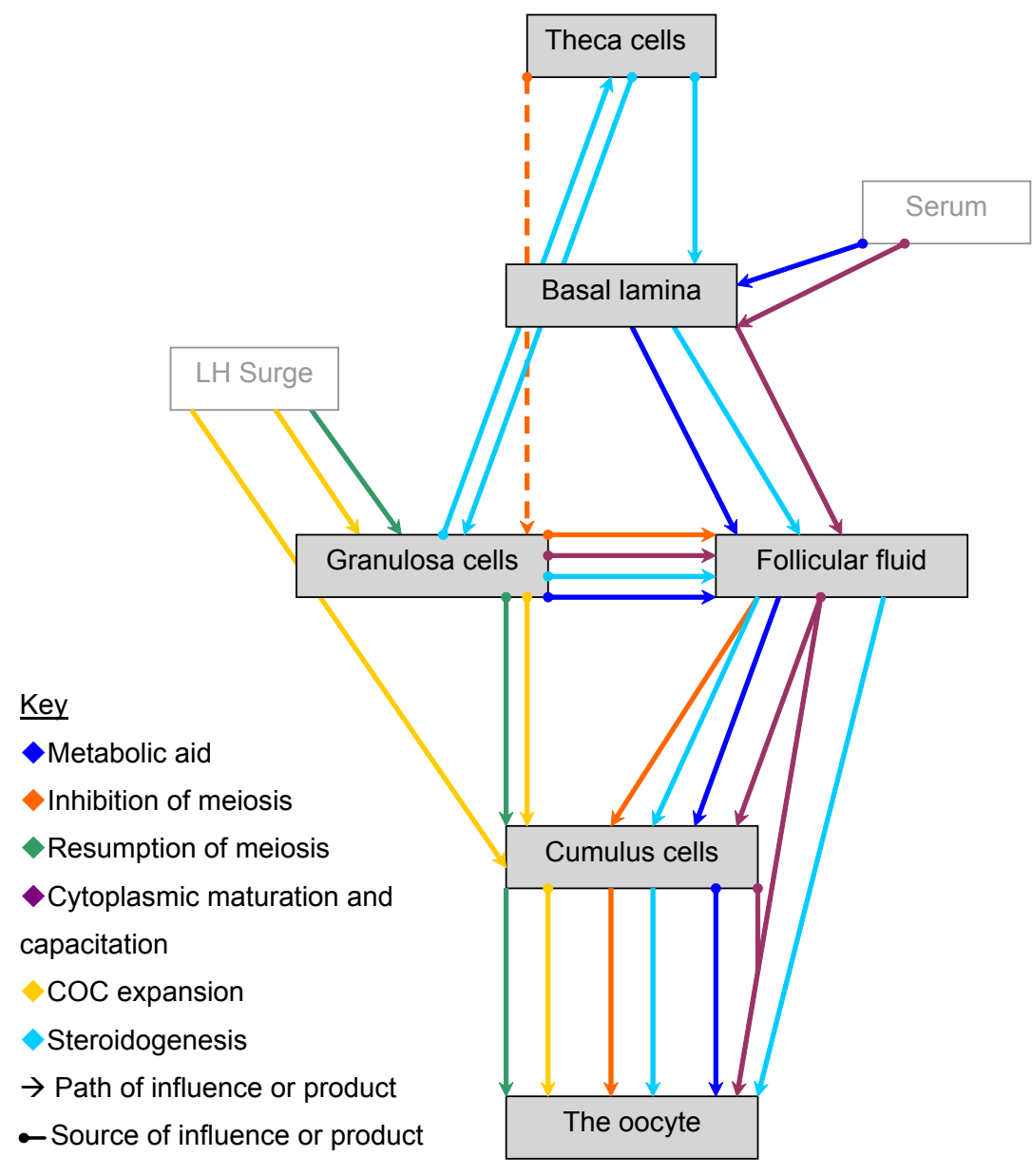

Fig. 3. The direct contributions of antral follicle components to oocyte differentiation. Color-coded arrows define contribution category ("contributions" include products, signals, and other influences). Absence of a circle at the base of an arrow indicates that the contributions necessarily travel through the compartment but do not originate in it. Each category of contribution may contain several points of origin; in these cases, new points of origin do not stop the path of contributions that originate earlier in the flowchart. Dashed line represents current uncertainty regarding theca cell involvement in meiotic regulation. Oocyte feedback and control of the follicular environment exists for every contribution category but is not shown here; it is discussed in the text. progesterone, and estradiol. In general, high follicular fluid concentrations of FSH, hCG, and LH seem to promote oocyte maturation and are correlated with a high probability of fertilization. High estradiol levels, especially in relation to androgen levels are also associated with high-quality oocytes and healthy follicles (reviewed Revelli et al., 2009). In response to some of these hormones, that participate in nuclear and cytoplasmic maturation; this indirect aspect of hormonal influence on oocyte differentiation is discussed in the subsequent section that addresses "somatic cells".

The direct genomic action of steroids on oocytes occurs via the binding of a nuclear steroid receptor with a steroid ligand, which then acts as a transcription factor. Oocytes express mRNA for estradiol receptors, indicating that direct genomic action of roids is possible in oocytes (Beker-van Woudenberg et al., 2004). The effect of estradiol on oocyte development, however, is controversial. In one study, direct non-genomic enhancement of cytoplasmic maturation by estradiol was described. A membrane-impermeable estradiol conjugate induced a rapid rise in free intracellular $\mathrm{Ca}^{2+}$ concentration, followed by a specific pattern of $\mathrm{Ca}^{2+}$ oscillations. Oocytes matured under this estradiol treatment also showed better fertilization and cleavage rates in vitro, while the progress of their nuclear maturation was unaffected (Tesarik and Mendoza, 1997). Together, the results of this study suggest that estradiol in the follicular fluid may exert a beneficial influence on cytoplasmic maturation by inducing calcium influx and oscillations via action at the level of the oocyte plasma membrane. Other studies, however, report that exposure of bovine oocytes to a membrane-impermeable estradiol conjugate during IVM had no effect on nuclear maturation, blastocyst formation, or embryo quality. Furthermore, exposure of bovine oocytes to estradiol (membrane-permeable) during IVM negatively impacts nuclear maturation and spindle organization (Beker-van Woudenberg et al., 2004). Interestingly, when estradiol was present during pre-maturation but absent during IVM, Beker-van Woudenberg et al., (2006) found that that nuclear and cytoplasmic maturation were unaffected compared to non-estradiol controls.

\section{Metabolites}

Follicular fluid contains metabolites that will accumulate within the oocyte and provide the necessary intra-cellular materials for oocyte differentiation. These metabolites include amino acids, lipids, nucleotides, and other small molecules, and are derived both from serum and from the metabolic activity of somatic follicular cells. In the bovine, metabolite levels in follicular fluid fluctuate with follicle dominance (Orsi etal., 2005), suggesting that subordinate follicles undergo different metabolic processes from dominant follicles containing pre-ovulatory oocytes.

At least 37 fatty acids have been identified in bovine follicular fluid. The most abundant are linoleic acid, oleic acid, stearic acid, and palmitic acid (Bender et al., 2010). During oocyte growth and maturation, the lipids in follicular fluid accumulate within the oocyte 
to form a cytoplasmic lipid reserve for future embryonic development. Evidence suggests that competent human oocytes generally contain relatively low levels of saturated fatty acids such as palmitic acid and stearic acid (Haggarty et al., 2006). Further, saturated fatty acid levels in the follicular fluid of a high-fertility bovine model (heifers) are lower than those of a low-fertility model (cows) (Bender et al., 2010).

Concentrations of linoleic acid, an n-6 polyusaturated acid and the most abundant fatty acid in bovine follicular fluid, decrease as follicular size increases. Indeed, this trend seems to be necessary for successful oocyte differentiation, as experimental exposure of COC's to linoleic acid inhibited cumulus cell expansion and decreased the number of oocytes reaching metaphase-II. Its effects were dose-dependent and altered discrete molecular mechanisms that regulate oocyte maturation (Marei et al., 2010).

All essential amino acids and most non-essential amino acids have lower concentrations in pre-ovulatory follicular fluid than in plasma, with the exception of glutamate, which exists in follicular fluid at a concentration three times higher than in plasma (Jozwik et al., 2006). The metabolic reaction converting glutamine to glutamate and ammonia in the oocyte is thought to be important in the synthesis of nucleic acid bases, which are required for the completion of meiosis. Indeed, Rieger and Loskutoff, 1994 showed that glutamine metabolism in bovine oocytes sharply increases after 18 hours of IVM, a phenomenon that may explain why glutamate levels are so high in preovulatory follicular fluid, as reported by Jozwik et al., (2006). Other metabolic substrates used by oocytes during maturation, such as glucose, pyruvate, and glycine, are also present in follicular fluid (Rieger and Loskutoff, 1994; PineroSagredo et al., 2010).

\section{Granulosa cells, cumulus cells, and theca cells}

The supportive role of somatic follicular cells in oocyte differentiation takes several forms. Each cell type is specialized to meet a discrete list of requirements for oocyte maturation and competence. Cumulus cells are intimately connected with the oocyte in the cumulus-oocyte complex and provide essential metabolic aid. Additionally, they participate in paracrine signaling that involves all cell types, including granulosa cells and theca cells, in the follicle. This signaling is key to regulating the progression of meiosis in the oocyte. Cumulus cells also modulate the transcriptional activity in the oocyte genome, and both granulosa cells and theca cells have important steroidogenic roles in the follicle. Much of their function is in turn guided by the oocyte, and consequently many studies have suggested that the health and functionality of somatic follicular cells is a reflection of oocyte health and competence, and vice-versa.

\section{Steroidogenesis}

Hormones govern the antral phase of folliculogenesis, and as such they are a pervasive influence in almost every aspect of somatic cell support to the oocyte. Although some hormones, such as $\mathrm{FSH}$ and $\mathrm{LH}$, are produced externally, others such as estradiol and androgens are produced within the follicle by granulosa and theca cells. The regulation of intrafollicular hormone levels is, in and of itself, a critical aspect of the antral follicle microenvironment. For instance, $\mathrm{GH}$ in follicular fluid enhances the FSH-dependent estradiol production by granulosa cells. Estradiol, in turn, upregulates androgen secretion by theca cells, a product that provides granulosa cells with the substrate necessary for further estradiol production. Androgen production by theca cells is also stimulated by $\mathrm{GH}$ and dependent on LH levels. Granulosa cells can synthesize inhibins that sensitize theca cells to $\mathrm{LH}$, thus facilitating further estradiol synthesis through the supply of androgens until the $\mathrm{LH}$ surge (reviewed by Knight and Glister, 2001; Kwintkiewicz and Giudice, 2009). As mentioned in a previous section, a dominantly estrogenic environment is correlated with oocyte competence. The hormones produced locally within the follicle, such as progesterone, anti-Mullerian hormone, and estradiol, will be involved in a variety of follicular modifications, signaling cascades, and metabolite production; this is further discussed below.

Supporting the growth, capacitation, and maturation of the oocyte

All three somatic cell types-granulosa cells, theca cells, and cumulus cells - secrete a variety of molecules that include proteins and growth factors, which have effects on the accumulation of necessary materials in the oocyte as well as the regulation of meiosis. The synthesis of many of these molecules is in response to hormonal triggers or instructions from the oocyte (see "The COC: a microenvironment within the follicle"). Cumulus cells, for example, can synthesize inhibin, activin, and follistatin - proteins that participate in multiple cell functions and signaling pathways. Transforming growth factor $\beta$ isoforms, and their receptors, are expressed by granulosa cells and theca cells at different times in folliculogenesis. While there is some controversy over their precise effects, they do appear to influence local hormone production, as well as theca and granulosa cell proliferation. Bone morphogenetic proteins (BMP) -4 and -7 are produced by theca cells in the rat and bovine, and influence cell proliferation, steroidogenesis, peptide hormone secretion, and FSH sensitivity in theca cells and granulosa cells (Knight and Glister, 2003). Finally, in response to cues from the oocyte, granulosa cells will secrete molecules such as hyaluronan (for the construction of the COC matrix).

In the course of development, oocytes need to acquire the molecular and cytoplasmic components that will support embryo development. To this end, it maintains an intimate and cooperative relationship with the cumulus cells surrounding it. Cumulus cells form gap junctions with the oocyte, traversing the zona pellucida barrier with structures called trans-zonal projections (TZP). Gap junctions allow small molecular weight molecules to be passed from cumulus cell to oocyte, such as ions, metabolites, amino acids, and signaling molecules.

Via these gap junctions and other modes of communication such as paracrine signaling, cumulus cells provide developmental assistance to the oocyte in several ways. Paracrine signaling between oocytes and the cells of the follicle is bidirectional and essential to development. In general terms, it has been demonstrated that the disruption of paracrine signaling between mouse oocytes and their cumulus cells in vitro reduces oocyte competence (Yeo et al., 2009). The details of paracrine signaling and its significance will be discussed in the section entitled, "The COC: a microenvironment within the follicle".

Through gap junctions, cumulus cells supply nutrients and energy substrates to the oocyte, including amino acids, glucose, and ribonucleosides (reviewed by Gilchrist et al., 2008). Oocytes are unable to metabolize glucose (Biggers et al., 1967), and can only generateATP through oxidative phosphorylation. However, cumulus cells can consume glucose via aerobic glycolysis, then send the product-pyruvate-to the oocyte for oxidative phosphorylation 
(reviewed by Gilchrist et al., 2008; Su et al., 2009). This may be particularly important during pre-ovulatory development, as the rate of pyruvate consumption in maturing metaphase-I oocytes is significantly higher than that in immature oocytes. Cumulus cells also help the oocyte take in amino acids. In the mouse, oocytes cannot efficiently take in all amino acids, meaning that cumulus cells must transfer them through gap junctions. Finally, cumulus cells cooperate with oocytes in cholesterol biosynthesis. As mouse oocytes do not express receptors for cholesterol, and studies suggest they lack the complete enzyme profile to synthesize cholesterol, cumulus cells must be the source of cholesterol for mouse oocytes (reviewed by Su et al., 2009). Although cumulus cells may synthesize cholesterol themselves, it is also possible that they take up cholesterol from follicular fluid with the help of apolipoprotein (apo) B-containing lipoproteins secreted by granulosa cells (recently reported by Gautier et al., 2010). Apolipoproteins help transport cholesterol into cells of various tissues. Indeed, apoB-containing lipoprotein content of follicular fluid is positively related to fertility parameters in women undergoing IVF (Gautier et al., 2010).

In addition to the metabolic support that they provide, cumulus cells are enormously important to oocyte cytoplasmic maturation and capacitation, although the exact nature of their influence is incompletely understood. Two events of cytoplasmic maturationthe stockpiling of proteins and transcripts, and the modification and rearrangement of organelles - have been linked to cumulus cell support. Pre-ovulatory oocyte development in vivo is accompanied by differential expressions of proteins in the COC, particularly around germinal vesicle breakdown (Dieleman et al., 2002). This is believed to contribute to the protein stores of the oocyte in anticipation of embryonic development. Experiments comparing the development of denuded oocytes with that of intact COCs have reported that spindle formation, mitochondrial congregation, and cortical granule distribution are impaired in denuded oocytes (Liu et al., 2005; Ge et al., 2008b). Furthermore, this defect can be partially corrected if denuded oocytes are matured with a cumulus cell monolayer in co-culture (Ge et al., 2008b).

Interestingly, cumulus cells appear to play their supportive roles through both direct and indirect contact with the oocyte. As described above, co-culture of denuded mouse oocytes with cumulus cells compensates at least in part for the absence of a COC and improves maturation or subsequent development, compared to denuded oocytes with no co-culture. However, physical contact with the oocyte is also indispensable for normal maturation. In a similar cumulus cell co-culture experiment with denuded mouse oocytes, a significant difference existed between the fates of corona-enclosed denuded oocytes and denuded oocytes with no corona cells. The competence of corona-enclosed denuded oocytes co-cultured with a cumulus cell monolayer was significantly superior according to parameters of oocyte activation and embryo development (Ge et al., 2008a). Furthermore, cumulus cell contact with the oocyte via TZPs was shown to regulate the cortical positioning of the germinal vesicle and meiotic spindle through an actin-dependent mechanism in the mouse (Barrett and Albertini, 2010).

Capacitation remains the most obscure step in oocyte differentiation. However, the importance of the follicular microenvironment to this specific event is well accepted. Although many oocytes from antral follicles can complete nuclear and cytoplasmic maturation in vitro, only a fraction will reach the blastocyst stage. Their ability to proceed in embryonic development is directly related to when they were removed from their follicle environment. For instance, one study reports that oocytes collected from dominant follicles prior to the LH surge had a $50 \%$ blastocyst rate in vitro, while those from smaller antral follicles had a $30 \%$ blastocyst rate (Hyttel et al., 1997). Evidently, the follicular microenvironment actively participates in oocyte development up to ovulation, contributing to oocyte stores at discrete intervals in folliculogenesis and oogenesis. This participation certainly involves cumulus cells.

\section{Modulating transcriptional activity in the oocyte genome}

Transcriptional activity in oocytes occurs throughout oocyte growth, but is repressed in fully grown oocytes prior to ovulation. These oocytes will rely on their accumulated mRNA stores to complete meiotic maturation and initial cleavage after fertilization. A 2001 study demonstrated that cumulus cells play an active role in the transcriptional activity of the oocyte genome in the mouse. In vitro, the presence of cumulus cells was necessary for normal repression of transcriptional activity, and for chromatin condensation and redistribution around the nucleolus (De La Fuente and Eppig, 2001).

More recently, Lee et al., (2008) reported a small number of transcriptional differences between rhesus monkey oocytes matured in vitro and in vivo. Interestingly, approximately $90 \%$ of the identified transcripts were upregulated or overexpressed in IVM oocytes. Many of these altered transcripts correspond to products regulated by interactions between the oocyte and somatic follicular cells, such as cell-cell adhesion and signaling. The results also imply functional alterations in steroid biosynthesis and metabolism, ion transport, cellular homeostasis, cell growth, stress response, and RNAbinding and translation. Similar findings regarding upregulation of transcripts in IVM or incompetent oocytes have been reported in rhesus monkeys and humans (Zheng et al., 2005; Jones et al., 2008). It seems likely that both the oocyte and its supportive somatic cells are sensitive to the maturation environment and that a disruption of that environment can, by upsetting oocyte-somatic cell interactions, affect the transcriptional activity of the oocyte.

\section{Regulating and facilitating the progression of meiosis}

Nuclear maturation automatically resumes in oocytes removed from their antral follicles. This phenomenon led to a number of studies, which unanimously conclude that the somatic cells of the follicle inhibit nuclear maturation in developing oocytes. This role of somatic cells is crucial to oocyte competence, as nuclear and cytoplasmic maturation must be synchronized before ovulation.

The inhibition of meiotic resumption in oocytes is caused by at least one pathway, mediated by cumulus cell, granulosa cell, and perhaps also theca cell communication. It is well established that intracellular concentrations of cAMP maintain meiotic arrest in oocytes, and that it is the fall of oocyte cAMP that leads to a resumption of meiosis. cAMP is generated in the oocyte by oocyte adenylyl cyclase, and it is consumed via hydrolysis due to oocyte cAMP-phosphodiesterase activity. Therefore, the inhibition of this enzyme is crucial to maintaining meiotic arrest. Recently, studies have shown that cyclic GMP (cGMP), which inhibits cAMPphosphodiesterase activity, is sent to oocytes by cumulus cells via gap junctions. In turn, cGMP is thought to be produced in cumulus cells in response to a factor secreted by granulosa cells 
into follicular fluid (reviewed by Conti et al., 2012). Therefore, the maintenance of meiotic arrest is an undertaking that involves the entire follicle. Interestingly, Richard and Sirard (1996) identified theca cells, rather than granulosa cells, as the somatic cell type ultimately responsible for the maintenance of meiotic arrest.

In vivo, the resumption of meiosis occurs in response to a surge in LH. Oocytes do not have LH receptors, and thus it is the somatic cells of the follicle (primarily granulosa cells, which have relatively more $\mathrm{LH}$ receptors than do cumulus cells) that must respond to the signal and initiate oocyte meiotic resumption. Currently, it seems that LH triggers a decrease in intra-cellular cGMP in somatic cells, and a MAP kinase-dependent disruption of the gap junctions linking granulosa cells with cumulus cells, which restricts the flow of cGMP into the oocyte (Norris et al., 2009). The activity of oocyte cAMP-phophodiesterase increases by five-fold and significantly lowers oocyte cAMP concentration, allowing meiosis to resume.

\section{Extracellular matrices}

\section{The basal lamina}

The basal lamina that encloses every follicle has an active role in folliculogenesis. As an extracellular matrix, it affects aspects of cell proliferation, fluid dynamics, structural and mechanical support of follicular and ovarian tissue, and extracellular signalling. It is believed to influence granulosa cell proliferation and differentiation, to exclude capillaries and white blood cells until ovulation, and to filter the molecules entering and exiting the follicle. Evidence suggests that granulosa cells produce many of the components of the follicular basal lamina (reviewed by Rodgers and Irving Rodgers, 2002).

There is some evidence that oocyte competence is linked to the physical profile of the basal lamina. In both the human and the bovine, antral follicles may have either a single layer of basal lamina aligned to the cell surface, or they may have additional layers of basal lamina. A multi-layered basal lamina is associated with columnar - rather than rounded-basal granulosa cells, and is hypothesized to represent older follicles (Irving-Rodgers et al., 2009). Recently, Irving-Rodgers et al., (2009) documented that healthy bovine antral follicles with a single layer of basal lamina have oocytes with significantly higher developmental competence (based on blastocyst yield), than healthy antral follicles with a multi-layered basal lamina do. Whether the phenotype of the basal lamina has a causal relationship with oocyte quality, or whether it simply reflects oocyte or follicle health, is unknown. In either case, the presence and role of the basal lamina is important for many aspects of follicle function. It is possible that the two phenotypes of basal lamina function differently and thus influence the follicular microenvironment.

The permeability of the basal lamina may increase as ovulation approaches. Changes in the structure of basal laminae from preantral follicles and antral follicles (Rodgers and Irving Rodgers, 2002), and the increased concentration of serum-derived proteins in the follicular fluid (Russell and Salustri, 2006)-necessary for COC expansion (see below)-suggest that this is the case.

The extracellular matrix of the cumulus-oocyte complex

In response to the pre-ovulatory surge of $\mathrm{LH}$, the $\mathrm{COC}$ begins rapid expansion and construction of an extracellular matrix. This unique matrix consists of long hyaluronan oligosaccharide chains, cross-linked with proteins and proteoglycans. The proper and timely assembly of the COC matrix is essential for ovulation, and several subsequent events that comprise the final steps in oocyte differentiation.

The components of the COC matrix are derived both from serum, and from somatic cell secretions within the follicle. Molecules from serum must pass through the basal lamina and reside in follicular fluid until utilized, and both cumulus cells and granulosa cells synthesize essential matrix components (reviewed by Russell and Salustri, 2006). Thus, the expansion of the COC matrix is yet another event that requires the participation of the entire follicle.

Studies in knockout mice have shown that the COC matrix is critical for ovulation and fertilization. It is through fertilization that the oocyte can complete its maturation, and therefore we will briefly discuss the COC matrix in that respect. Mice lacking the expression of certain matrix proteins had a $50 \%$ reduced rate of ovulation, suggesting that the physical characteristics of a normal matrix enable the COC to deform and pass through the ruptured follicle wall. Subsequently, the COC matrix also heavily influences fertilization success. Sperm will come into contact with the matrix before the oocyte, and molecules in the matrix contribute to sperm capacitation. Other roles, such as a chemoattractant for sperm, and a "sperm quality filter," have been hypothesized for the COC matrix. Once again, knockout studies in mice testify to the indispensability of the COC matrix for fertilization (reviewed by Russell and Salustri, 2006).

The construction of the COC matrix depends on guiding signals from the oocyte, and represents one of the final chapters in a lifetime of cross-talk between the oocyte and its follicle. The next section will briefly review the oocyte-driven dynamics of the COC and antral folliculogenesis.

\section{The cumulus-oocyte complex: a microenvironment within the follicle}

Thus far, this review has presented many ways in which the antral follicle contributes to oocyte differentiation. However, the follicular microenvironment upon which the oocyte depends is cultivated and directed by the oocyte itself. This cyclic relationship, in which the oocyte shapes the developmental milieu that is ultimately responsible for its competence, is mediated through gap junctional communication and secreted factors within the COC. As such, the COC creates a microenvironment within the follicle in which intimate bidirectional cross-talk, signal transduction, and cell-cell contact occur.

The previous sections detail the ways in which various components of the antral follicle support oocyte development, such as cumulus cells providing metabolic aid to the oocyte. Many of these contributions are coordinated or stimulated by the oocyte. For instance, the control of metabolic activity in cumulus cells, such as glycolysis, amino acid uptake, and cholesterol synthesis, are under paracrine control by the oocyte (reviewed by Su et al., 2009). Through secreted factors the oocyte also regulates the production of steroids and other factors in follicular cells, LH receptors on cumulus and granulosa cells, hyaluronic acid for the COC matrix, cumulus expansion, and cumulus survival (reviewed by Hutt and Albertini, 2007). For a more comprehensive list of oocyte-secreted factors and their effects, see Gilchrist et al., (2008).

Among the myriad oocyte-secreted factors that target somatic 
cell function in the oocyte, two heavily studied factors, growth differentiation factor 9 (GDF9) and bone morphogenetic protein 15 (BMP15), are secreted by most mammalian oocytes. These members of the TGF $\beta$ superfamily are not yet thoroughly understood, but they are thought to be involved in cumulus cells/granulosa cells differentiation and prevention of apoptosis, cumulus cell metabolic activity, COC matrix expansion, and overall normal follicular development and ovulation (reviewed by Gilchrist et al., 2008; Su et al., 2009). As mentioned earlier, cumulus and granulosa cells secrete inhibin, activin, and follistatin. Oocytes express activin receptors, which could constitute one of the signaling pathways within the COC (Knight and Glister, 2003). Bidirectional communication in the $\mathrm{COC}$ may be a way for the oocyte to ensure that its deficiencies are compensated for, and its needs met, by the antral follicle.

Based on the information summarized above, the actions of the oocyte itself are crucial to oocyte differentiation. Therefore, it and the COC deserve mention as components of the antral follicle that contribute to oocyte differentiation. In the next section, the impact of discrete events in antral folliculogenesis on oocyte differentiation will be discussed.

\section{Oocyte differentiation: developmental mile- stones in folliculogenesis}

\section{Growing in size}

There exists a positive relationship between the diameter of the antral follicle and the in vitro developmental competence of the enclosed oocyte (Hyttel et al., 1997). However, the size of the antral follicle alone does not reveal the full spectrum of follicular stages that modulate the developmental competence of the enclosed oocyte. Indeed, while the proportion of developmentally competent oocytes rise with growth of antral follicles, small antral follicles can still contain such oocytes. Other differences in follicle characteristics (e.g. follicle dominance and atresia) can influence oocyte competence, and as such they merit consideration.

\section{Achieving and maintaining dominance}

The decisive transitions that antral follicles undergo most likely influence the oocyte. The follicle selected for dominance harbors the oocyte that will become ovulated, and as such it must provide the ideal microenvironment to support complete developmental acquisition by the oocyte. It is thus of utmost importance to identify features unique to the dominant follicle and interpret them through the lens of oocyte development. Candidate genes include those found in dominant but not subordinate follicles (Zielak et al., 2007), or only in granulosa cells surrounding a developmentally competent oocyte (Robert et al., 2001). The follicular fluid also differs significantly during the selection phase, notably with respect to the hormonal milieu (for estradiol, inhibin, insulin-like growth factor-binding proteins) (Austin et al., 2001; Fortune et al., 2004). Of particular relevance will be follicular differences that are mechanistically linked with oocyte competence.

Often the characterization of the dominant follicle milieu is conducted shortly after the establishment of dominance; this is indeed a critical transition to define. However, further insight can be gained from the evaluation of the follicular milieu during the maintenance of follicle dominance, as the follicle augments its growth dramatically (from $\sim 8 \mathrm{~mm}$ up to $20 \mathrm{~mm}$ in the bovine), and as it attains pre-ovulatory status. Only a few studies have focused on this phase. Yet in that time, the oocyte undergoes the complex processes of capacitation and maturation in a changing environment, notably with respect to steroids and growth factors.

Once dominance is established, non-selected follicles contain oocytes of inferior developmental competence, compared to similarly sized follicles obtained when the dominant follicle has not yet been selected (Hagemann, 1999). Such a difference may be explained in part by the fact that subordinate follicles will follow a very different fate from the dominant follicle, namely regression 
and eventual atresia. Relationships between follicle atresia and oocyte competence must thus be considered, especially since atresia is a probable destiny of most antral follicles.

\section{Undergoing atresia}

With the exception of the dominant follicle, all other antral follicles in the cohort undergo atresia. When atretic, the follicle microenvironment differs significantly from the one in a healthy follicle, including marked changes in steroids, growth factors, and granulosa cell apoptosis (reviewed by Irving-Rodgers et al., 2001). The influence of atresia on oocyte competence is dynamic. Advanced stages of atresia are associated with oocyte of poor quality (Sirard et al., 1999; Hendriksen et al., 2004), while early atretic follicles reportedly contain oocytes of increased developmental potential when compared to non-atretic follicles (Blondin and Sirard, 1995; Salamone et al., 1999). Mechanistically, similar morphological and biochemical changes characterize the follicular microenvironments of pre-ovulatory and early atretic follicles (Kruip and Dieleman, 1989; Assey et al., 1994; Blondin and Sirard, 1995). As a result, the oocytes from early atretic follicles may be able to undergo final capacitation steps in a follicular milieu comparable to pre-ovulation.

\section{Beyond dominance}

The timing of follicular dominance as a temporal window during which the oocyte is of maximal potential also merits investigation. In instances when the period of dominance of the ovulatory follicle is extended experimentally, decreased pregnancy rates (Mihm et al., 1994) or conversely, retention of developmental competence (Oussaid et al., 2000) were reported. Interestingly, the use of a gonadotropin releasing hormone antagonist for manipulating the duration of follicle dominance resulted in atresia (early or advanced) in large preovulatory follicles with the oocyte retaining their competencies, suggesting the potential existence of a "point of no return" for the acquisition of developmental potential (Oussaid et al., 2000). In contrast, the use of progestins to extend follicle dominance yielded oocytes showing signs of aging, thereby explaining their reduced fertility after ovulation (Mihm et al., 1999). Future studies remain to elucidate the ability of oocytes from preovulatory follicles to maintain their developmental potential, ideally under non-stimulated conditions.

Following its growth, the dominant follicle reaches a plateau phase at which point further biochemical differentiation takes place prior to the ovulatory surge. The peri-ovulatory period must also be considered when examining the follicular microenvironment since it is the time during which the oocyte undergoes maturation. Upon the LH surge, the dominant follicle undergoes a shift in steroidogenic activity (with increased progesterone and decreased estrogen production) and changes in prostaglandins and metalloproteinases (Fortune et al., 2009). While an understanding of the regulation of meiotic progression by LH has accrued (Conti et al., 2012), studies remain to detail the effects of intrafollicular changes on the developmental potential of the oocyte during the peri-ovulatory period. One step in an insightful direction includes the importance of ADAMTS1 (a metalloproteinase upregulated within the follicle following the LH/FSH surge) in the formation of a COC matrix that is poised for fertilization (Fortune et al., 2009; Brown et al., 2010).

Together, these studies testify to the dynamic and complex relationship between oocyte differentiation and the progression of antral folliculogenesis (Fig. 4). Research to date has identified windows in follicular development during which the oocyte possesses superior developmental competence, for example during follicle dominance and atresia. Yet the particulars of how the developmental transitions of the antral follicle influence oocyte quality remain uncharted.

\section{Oocyte differentiation: clinical relevance of the antral follicle}

There is an undeniable clinical relevancy to mastering the influences of the antral follicle microenvironment on oocyte differentiation (Fig. 5). Indeed, applications exist for both agricultural and human ART, notably in the realm of detection, prevention, and management of infertility.

\section{Optimizing In vitro Maturation (IVM)}

The follicular environment nurtures the oocyte in a multitude of ways; it is thus pivotal to understand these influences in complete detail, particularly as there is a clinical need to mature oocytes in vitro (Nogueira et al., 2012). Our current ability to mature oocytes in vitro leaves much to be desired, and one culprit may be our incomplete mastery of the specialized niche that is the follicle as it supports oocyte development.

It is really not surprising that current in vitro culture systems fail to support the differentiation of oocytes with maximal developmental potential. Indeed, only few of the follicular features are either maintained (with the culture of intact COCs) or mimicked (with media supplementation) in vitro. Yet, the support from granulosa cells, follicular fluid, basal lamina, and theca cells are missing altogether. Innovative attempts to compensate for the physiological conditions of the follicular milieu include the culture of oocytes or follicles in a three-dimensional environment. However, one must also consider that there are stresses unique to in vitro culture conditions and alien to the in vivo antral follicle. Thus, culture strategies may also need to be tailored to the features of in vitro conditions; regardless, a mastery of the in vivo microenvironment will direct efforts aimed at helping the oocyte develop in vitro. Primarily, such an understanding will permit us to see what is missing in vitro, as well as what is new in vitro-thus focusing treatments to help the oocyte cope with exogenous influences and develop as normally as possible under artificial conditions. Currently, in vivo maturation remains superior to IVM, and one fundamental step compromised in vitro is oocyte capacitation. In human and cattle, capacitation would not occur or be interrupted for oocytes retrieved from $<8$ $\mathrm{mm}$ and $>8 \mathrm{~mm}$ antral follicles, respectively.

\section{Ensuring oocyte capacitation- in vitro and in vivo}

Given that capacitation may be a limiting factor in the expression of full developmental competence, two approaches exist. Both approaches (one in vitro and the other in vivo) aim to ensure that capacitation takes place in all retrieved oocytes.

In vitro, capacitation could be coerced and mimicked when attempting to mature oocytes obtained from follicles other than the dominant, preovulatory one. When released from the follicle, the oocyte spontaneously resumes meiosis; this non-physiological event interferes with the coordination and completion of differentiation processes. It follows that a meiotic arrest strategy may allow events taking place in the COC to progress further than they would otherwise in vitro (Gilchrist, 2011). Even with this strategy, however, 
the oocyte may not remain under the influence of cumulus cells for as long as it would in vivo; additionally, influences from other follicular compartments are still missing. Exogenous supplementation may be designed to make up for some of these influences. Results to date only show limited successes, thereby warranting novel approaches that more closely mirror follicular conditions. More recently, a two-phase approach (pre-IVM and extended IVM) combining the use of FSH and meiotic arrestors showed promising improvements in developmental competence (Albuz et al., 2010).

Modification of in vivo conditions prior to oocyte retrieval may hold the key to improving the quality of oocytes worked with in vitro. Manipulations could target the support of the most optimal follicular environment, that is to say, one that maintains the appropriate follicle-oocyte interactions. Coasting protocols, for example, entail the collection of immature oocytes from follicles in a plateau phase of growth; follicular atresia may thus be initiated, thereby creating a follicular microenvironment that permits oocyte capacitation (see earlier section on atresia). In the bovine, this is achieved by FSH exposures prior to a period of coasting with no gonadotropin stimulation (Sirard et al., 1999). A time of $54 \pm 7$ hours post-FSH withdrawal was recently identified as optimal for the retrieval of multiple oocytes with highest developmental potential (Nivet et al., 2012). This is one clear instance when an augmented understanding of follicular influences on the oocyte leads to significant clinical improvement.

\section{Predicting oocyte quality}

Oocytes vary greatly in their developmental potential, and identifying follicular factors that signify an oocyte of superior quality (i.e. one that has completed all of the preparatory steps) will prove invaluable. In human ART, this would facilitate the selection of high quality oocytes and, in turn, the transfer of a single embryo, thereby controlling the incidence of multiple pregnancies. In experimental studies, the establishment of reliable biomarkers of oocyte quality would facilitate further advances, as for example in the optimization of culture media or the testing of various manipulations. Given the complexity of follicular interactions, the solution will likely be found in the use of a combination of multiple markers. Efforts to date have identified candidate biomarkers in follicular fluid, granulosa cells, and cumulus cells as indicators of oocyte quality (Robert et al., 2001; Revelli et al., 2009; Assidi et al., 2010). Further validation is warranted.

Appraising exogenous influences on the antral follicle microenvironment, and in turn on the oocyte

Antral folliculogenesis is a phase of follicle and oocyte development that is susceptible to damage (reviewed by Fair, 2010). To identify potential pathologies and address the roots of their causes, it is relevant to first define normal processes. Environmental stressors may act not directly on the oocyte but rather on other compartments of the follicle. Clearly, if the follicular milieu is perturbed,

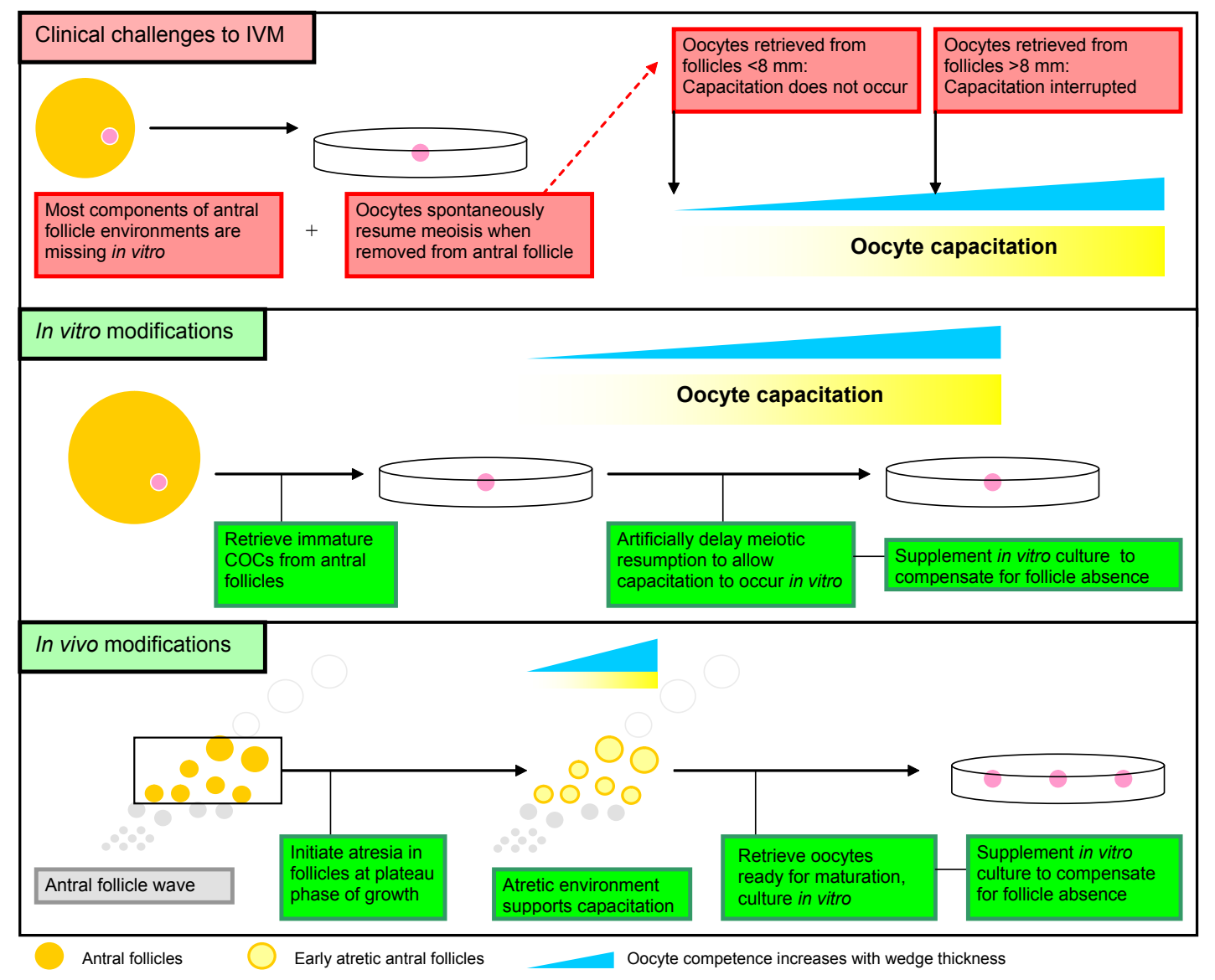

Fig. 5. The absence of the antral follicle environment remains an obstacle to in vitro maturation (IVM) success and other clinical assisted reproductive technology (ART) protocols. Solutions to the problem have been attempted both in vivo and in vitro. 
normal oocyte development will be affected. Thus, studies that evaluate the potential effects of any exogenous factor should not limit their assessment to oocytes alone, but rather expand their analyses to follicular fluid and follicle cells. For example, lactation and nutrition may exert their influences on fertility via effects on the oocyte, either directly or indirectly following modifications in follicular features. Indeed, steroid synthesis is altered in dominant follicles from cows with metabolic profiles associated with lactation and acute dietary restriction (Walsh et al., 2012). This type of evidence promises to help manage animals and patients more effectively so as to maximize reproductive potential and the development of healthy offsprings.

Advanced maternal age also exerts its influences on the antral follicle and the oocyte. Follicle ageing has been associated with changes in gene expression, mitochondrial activity, oxidative stress, and vascularization, all of which may impair oocyte function (reviewed by Tatone et al., 2008). Older cows are characterized by alterations in follicle dynamics together with a reduced developmental competence of the oocytes (Malhi et al., 2005; Malhi et al., 2007). On the other side of the age spectrum, oocytes from prepubertal animals (such as in cows and pigs) display reduced developmental competence when compared to oocytes from adult animals. Interestingly, differences exist in the follicular environments, notably in the steroid content of follicular fluid, between adult and prepubertal animals (Grupen et al., 2003). Yet, as long as the size of the follicle that the oocyte originates from is high enough, the oocyte possesses similar developmental competence between prepubertal and adult animals, supporting the capability of prepubertal oocytes to complete the capacitation process (Kauffold et al., 2005). Further studies should thus focus on causal relationships between prepubertal or ageing follicular microenvironments and oocyte quality.

Many challenges reside in the management and treatment of infertility. While strategies already exist, a comprehensive and detailed view of how the oocyte comes to acquire developmental competence remains to be attained. Many of the answers may lie in an understanding of, as well as an ability to modulate, the antral follicular microenvironment

\section{Conclusion}

Every egg needs a nest. In the mammalian reproductive system, oocyte development occurs within the highly specialized microenvironment of an ovarian follicle. The follicle is tasked with facilitating the complex and sensitive process of oogenesis, and as such it constitutes a multifaceted developmental niche for the oocyte.

In an antral follicle, this developmental niche is comprised of several layers, each conferring additional protection and specialized attention to the oocyte. In this review, we have discussed the roles of each component of the antral follicle, from the outer theca layer and basal lamina, to the nutrient-rich buffer of follicular fluid, to the microenvironment-within-a-microenvironment known as the COC. Although each part of the follicle-and each stage of folliculogenesis - serves a unique purpose, successful oocyte differentiation ultimately depends on the cooperation and coordination of antral follicle function as a whole. Thus, to understand final oocyte differentiation, we must elucidate the functions of antral follicle compartments, as well as their relationship to one another.

In view of the growing field of ART, further efforts should continue unraveling how the components of this specialized niche guide oocyte differentiation. It is clear that the removal of oocytes from their follicular environment must be compensated for, if oocyte differentiation is to progress normally in vitro. A grasp of the antral follicle may enable the field to obtain oocytes of maximal quality and to recapitulate the native niche of the oocyte in vitro. This would, in turn, minimize the loss or waste of oocytes and embryos, as well as increase the success rate of clinical procedures.

The ability of the oocyte to modulate the features of its developmental niche is an incompletely understood aspect of the antral follicle microenvironment. However, the resulting co-dependency between oocytes and their follicles presents an additional hurdle for the in vitro culture of oocytes during ART. Not only must ART attempt to replicate the essential components of the follicular microenvironment for the benefit of oocytes in vitro, but it must also strive to understand how, when, and why the oocyte induces changes to that follicular microenvironment.

The antral follicle is a specialized niche for oocyte differentiation. Although the relationship between the oocyte and its follicle are dazzlingly complex, the follicular niche is in essence a nest for a very special egg. It is perhaps doubly appropriate, then, that the word "niche" derives from the Middle French, "to nest."

\section{Acknowledgement}

This project was supported by Agriculture and Food Research Initiative Competitive Grant no. 2011-67016-20041 from the USDA National Institute of Food and Agriculture.

\section{References}

ALBUZ, F.K., SASSEVILLE, M., LANE, M., ARMSTRONG, D.T., THOMPSON, J.G. GILCHRIST, R.B. (2010). Simulated physiological oocyte maturation (SPOM): a novel in vitro maturation system that substantially improves embryo yield and pregnancy outcomes. Hum. Reprod. 25: 2999-3011.

ASSEY, R.J., HYTTEL, P., GREVE, T., PURWANTARA, B. (1994). Oocyte morphology in dominant and subordinate follicles. Mol. Reprod. Dev. 37: 335-344.

ASSIDI, M., DIELEMAN, S.J., SIRARD, M.A. (2010). Cumulus cell gene expression following the LH surge in bovine preovulatory follicles: potential early markers of oocyte competence. Reproduction. 140: 835-852.

AUSTIN, E.J., MIHM, M., EVANS, A.C., KNIGHT, P.G., IRELAND, J.L., IRELAND, J.J., ROCHE, J.F. (2001). Alterations in intrafollicular regulatory factors and apoptosis during selection of follicles in the first follicular wave of the bovine estrous cycle. Biol. Reprod. 64: 839-848.

BARRETT, S.L., ALBERTINI, D.F. (2010). Cumulus cell contact during oocyte maturation in mice regulates meiotic spindle positioning and enhances developmental competence. J. Assist. Reprod. Genet. 27: 29-39.

BEKER-VAN WOUDENBERG, A.R., VAN TOL, H.T., ROELEN, B.A., COLENBRANDER, B., BEVERS, M.M. (2004). Estradiol and its membrane-impermeable conjugate (estradiol-bovine serum albumin) during in vitro maturation of bovine oocytes: effects on nuclear and cytoplasmic maturation, cytoskeleton, and embryo quality. Biol. Reprod. 70: 1465-1474.

BEKER-VAN WOUDENBERG, A.R., ZEINSTRA, E.C., ROELEN, B.A., COLENBRANDER, B., BEVERS, M.M. (2006). Developmental competence of bovine oocytes after specific inhibition of MPF kinase activity: effect of estradiol supplementation and follicle size. Anim. Reprod. Sci. 92: 231-240.

BENDER, K., WALSH, S., EVANS, A.C., FAIR, T., BRENNAN, L. (2010). Metabolite concentrations in follicular fluid may explain differences in fertility between heifers and lactating cows. Reproduction. 139: 1047-1055.

BIGGERS, J.D., WHITTINGHAM, D.G., DONAHUE, R.P. (1967). The pattern of energy metabolism in the mouse oocyte and zygote. Proc. Natl. Acad. Sci. USA. 58: $560-567$.

BLONDIN, P., SIRARD, M.A. (1995). Oocyte and follicular morphology as determining characteristics for developmental competence in bovine oocytes. Mol. Reprod. 
Dev. 41: 54-62.

BROWN, H.M., DUNNING, K.R., ROBKER, R.L., BOERBOOM, D., PRITCHARD, M., LANE, M., RUSSELL, D.L. (2010). ADAMTS1 cleavage of versican mediates essential structural remodeling of the ovarian follicle and cumulus-oocyte matrix during ovulation in mice. Biol. Reprod. 83: 549-557.

CHOI, W.J., BANERJEE, J., FALCONE, T., BENA, J., AGARWAL, A., SHARMA, R.K. (2007). Oxidative stress and tumor necrosis factor-alpha-induced alterations in metaphase II mouse oocyte spindle structure. Fertil. Steril. 88: 1220-1231.

COMBELLES, C.M., HOLICK, E.A., PAOLELLA, L.J., WALKER, D.C., WU, Q. (2010). Profiling of superoxide dismutase isoenzymes in compartments of the developing bovine antral follicles. Reproduction. 139: 871-881.

CONTI, M., HSIEH, M., ZAMAH, A.M., OH, J.S. (2012). Novel signaling mechanisms in the ovary during oocyte maturation and ovulation. Mol. Cell. Endocrinol.356:65-73.

DE LA FUENTE, R., EPPIG, J.J. (2001). Transcriptional activity of the mouse oocyte genome: companion granulosa cells modulate transcription and chromatin remodeling. Dev. Biol. 229: 224-236.

DIELEMAN, S.J., HENDRIKSEN, P.J., VIUFF, D., THOMSEN, P.D., HYTTEL, P., KNIJN, H.M., WRENZYCKI, C., KRUIP, T.A., NIEMANN, H., GADELLA, B.M., BEVERS, M.M., VOS, P.L. (2002). Effects of in vivo prematuration and in vivo final maturation on developmental capacity and quality of pre-implantation embryos. Theriogenology. 57: 5-20.

FAIR, T. (2003). Follicular oocyte growth and acquisition of developmental competence. Anim. Reprod. Sci. 78: 203-216.

FAIR, T. (2010). Mammalian oocyte development: checkpoints for competence. Reprod. Fertil. Dev. 22: 13-20.

FAIR, T., HULSHOF, S.C., HYTTEL, P., GREVE, T., BOLAND, M. (1997). Nucleus ultrastructure and transcriptional activity of bovine oocytes in preantral and early antral follicles. Mol. Reprod. Dev. 46: 208-215.

FORTUNE, J.E., RIVERA, G.M., YANG, M.Y. (2004). Follicular development: the role of the follicular microenvironment in selection of the dominant follicle. Anim. Reprod. Sci. 82-83: 109-126.

FORTUNE, J.E., WILLIS, E.L., BRIDGES, P.J., YANG, C.S. (2009). The periovulatory period in cattle: progesterone, prostaglandins, oxytocin and ADAMTS proteases. Anim. Reprod. 6: 60-71.

GANDOLFI, T.A., GANDOLFI, F. (2001). The maternal legacy to the embryo: cytoplasmic components and their effects on early development. Theriogenology. 55: $1255-1276$

GAUTIER, T., BECKER, S., DROUINEAUD, V., MENETRIER, F., SAGOT, P., NOFER, J.R., VON OTTE, S., LAGROST, L., MASSON, D., TIETGE, U.J. (2010). Human luteinized granulosa cells secrete apoB100-containing lipoproteins. J. Lipid. Res. 51: 2245-2252.

GE, L., HAN, D., LAN, G.C., ZHOU, P., LIU, Y., ZHANG, X., SUI, H.S., TAN, J.H. (2008a). Factors affecting the in vitro action of cumulus cells on the maturing mouse oocytes. Mol. Reprod. Dev. 75: 136-142.

GE, L., SUI, H.S., LAN, G.C., LIU, N., WANG, J.Z., TAN, J.H. (2008b). Coculture with cumulus cells improves maturation of mouse oocytes denuded of the cumulus oophorus: observations of nuclear and cytoplasmic events. Fertil. Steril. 90: 2376-2388.

GILCHRIST, R.B. (2011). Recent insights into oocyte-follicle cell interactions provide opportunities for the development of new approaches to in vitro maturation. Reprod. Fertil. Dev. 23: 23-31.

GILCHRIST, R.B., LANE, M., THOMPSON, J.G. (2008). Oocyte-secreted factors: regulators of cumulus cell function and oocyte quality. Hum. Reprod. Update. 14: $159-177$.

GRUPEN, C.G., MCILFATRICK, S.M.,ASHMAN, R.J., BOQUEST,A.C.,ARMSTRONG, D.T., NOTTLE, M.B. (2003). Relationship between donor animal age, follicular fluid steroid content and oocyte developmental competence in the pig. Reprod. Fertil. Dev. 15: 81-87.

GUPTA, S., CHOI, A., YU, H.Y., CZERNIAK, S.M., HOLICK, E.A., PAOLELLA, L.J., AGARWAL, A., COMBELLES, C.M. (2011). Fluctuations in total antioxidant capacity, catalase activity and hydrogen peroxide levels of follicular fluid during bovine folliculogenesis. Reprod. Fertil. Dev. 23: 673-680.

HAGEMANN, L.J. (1999). Influence of the dominant follicle on oocytes from subordinate follicles. Theriogenology. 51: 449-459.

HAGGARTY, P., WOOD, M., FERGUSON, E., HOAD, G., SRIKANTHARAJAH, A., MILNE, E., HAMILTON, M., BHATTACHARYA, S. (2006). Fatty acid metabolism in human preimplantation embryos. Hum. Reprod. 21: 766-773.

HENDRIKSEN, P.J., STEENWEG, W.N., HARKEMA, J.C., MERTON, J.S., BEVERS M.M., VOS, P.L., DIELEMAN, S.J. (2004). Effect of different stages of the follicular wave on in vitro developmental competence of bovine oocytes. Theriogenology. 61: $909-920$

HUTT, K.J., ALBERTINI, D.F. (2007). An oocentric view of folliculogenesis and embryogenesis. Reprod. Biomed. Online. 14: 758-764.

HYTTEL, P., FAIR, T., CALLESEN, H., GREVE, T. (1997). Oocyte growth, capacitation and final maturation in cattle. Theriogenology. 47: 23-32.

IRVING-RODGERS, H.F., MORRIS, S., COLLETT, R.A., PEURA, T.T., DAVY, M. THOMPSON, J.G., MASON, H.D., RODGERS, R.J. (2009). Phenotypes of the ovarian follicular basal lamina predict developmental competence of oocytes. Hum. Reprod. 24: 936-944.

IRVING-RODGERS, H.F., VANWEZEL, I.L., MUSSARD, M.L., KINDER, J.E., RODGERS, R.J. (2001). Atresia revisited: two basic patterns of atresia of bovine antral follicles. Reproduction. 122: 761-775.

JONES, G.M., CRAM, D.S., SONG, B., MAGLI, M.C., GIANAROLI, L., LACHAMKAPLAN, O., FINDLAY, J.K., JENKIN, G., TROUNSON, A.O. (2008). Gene expression profiling of human oocytes following in vivo or in vitro maturation. Hum. Reprod. 23: 1138-1144.

JOZWIK, M., JOZWIK, M., TENG, C., BATTAGLIA, F.C. (2006). Amino acid, ammonia and urea concentrations in human pre-ovulatory ovarian follicular fluid. Hum. Reprod. 21: 2776-2782.

KAUFFOLD, J., AMER, H.A., BERGFELD, U., WEBER, W., SOBIRAJ, A. (2005). The in vitro developmental competence of oocytes from juvenile calves is related to follicular diameter. J. Reprod. Dev. 51: 325-332.

KNIGHT, P.G., GLISTER, C. (2001). Potential local regulatory functions of inhibins, activins and follistatin in the ovary. Reproduction. 121: 503-512.

KNIGHT, P.G., GLISTER, C. (2003). Local roles of TGF-beta superfamily members in the control of ovarian follicle development. Anim. Reprod. Sci. 78: 165-183.

KRUIP, T.A., DIELEMAN, S.J. (1989). Intrinsic and extrinsic factors influencing steroid production in vitro by bovine follicles. Theriogenology. 31: 531-544.

KWINTKIEWICZ, J., GIUDICE, L.C. (2009). The interplay of insulin-like growth factors, gonadotropins, and endocrine disruptors in ovarian follicular development and function. Semin. Reprod. Med. 27: 43-51.

LEE, Y.S., LATHAM, K.E., VANDEVOORT, C.A. (2008). Effects of in vitro maturation on gene expression in rhesus monkey oocytes. Physiol. Genomics. 35: 145-158.

LIU, X.Y., MAL, S.F., MIAO, D.Q., LIU, D.J., BAO, S., TAN, J.H. (2005). Cortical granules behave differently in mouse oocytes matured under different conditions. Hum. Reprod. 20: 3402-3413.

MALHI, P.S., ADAMS, G.P., MAPLETOFT, R.J., SINGH, J. (2007). Oocyte developmental competence in a bovine model of reproductive aging. Reproduction. 134: 233-239.

MALHI, P.S., ADAMS, G.P., SINGH, J. (2005). Bovine model for the study of reproductive aging in women: follicular, luteal, and endocrine characteristics. Biol. Reprod. 73: 45-53.

MAREI, W.F., WATHES, D.C., FOULADI-NASHTA, A.A. (2010). Impact of linoleic acid on bovine oocyte maturation and embryo development. Reproduction. 139:979-988.

MIHM, M., BAGUISI, A., BOLAND, M.P., ROCHE, J.F. (1994). Association between the duration of dominance of the ovulatory follicle and pregnancy rate in beef heifers. J. Reprod. Fertil. 102: 123-130.

MIHM, M., CURRAN, N., HYTTEL, P., KNIGHT, P.G., BOLAND, M.P., ROCHE, J.F (1999). Effect of dominant follicle persistence on follicular fluid oestradiol and inhibin and on oocyte maturation in heifers. J. Reprod. Fertil. 116: 293-304.

NIVET, A.L., BUNEL, A., LABRECQUE, R., BELANGER, J., VIGNEAULT, C., BLONDIN, P., SIRARD, M.A. (2012). FSH withdrawal improves developmental competence of oocytes in the bovine model. Reproduction. 143: 165-171.

NOGUEIRA, D., SADEU, J.C., MONTAGUT, J. (2012). In vitro oocyte maturation: current status. Semin. Reprod. Med. 30: 199-213.

NORRIS, R.P., RATZAN, W.J., FREUDZON, M., MEHLMANN, L.M., KRALL, J. MOVSESIAN, M.A., WANG, H., KE, H., NIKOLAEV, V.O., JAFFE, L.A. (2009). Cyclic GMP from the surrounding somatic cells regulates cyclic AMP and meiosis in the mouse oocyte. Development. 136: 1869-1878.

O'DOHERTY, A.M., O'SHEA, L.C., FAIR, T. (2012). Bovine DNA methylation imprints are established in an oocyte size-specific manner, which are coordinated with the 
expression of the DNMT3 family proteins. Biol. Reprod. 86: 67.

ORSI, N.M., GOPICHANDRAN, N., LEESE, H.J., PICTON, H.M., HARRIS, S.E. (2005). Fluctuations in bovine ovarian follicular fluid composition throughout the oestrous cycle. Reproduction. 129: 219-228.

OUSSAID, B., LONERGAN, P., KHATIR, H., GULER, A., MONNIAUX, D., TOUZE, J.L., BECKERS, J.F., COGNIE, Y., MERMILLOD, P. (2000). Effect of GnRH antagonistinduced prolonged follicular phase on follicular atresia and oocyte developmental competence in vitro in superovulated heifers. J. Reprod. Fertil. 118: 137-144.

PINERO-SAGREDO, E., NUNES, S., DELOS SANTOS, M.J., CELDA, B., ESTEVE, V. (2010). NMR metabolic profile of human follicular fluid. NMRBiomed. 23: 485-495.

REVELLI, A., DELLE PIANE, L., CASANO, S., MOLINARI, E., MASSOBRIO, M., RINAUDO, P. (2009). Follicular fluid content and oocyte quality: from single biochemical markers to metabolomics. Reprod. Biol. Endocrinol. 7: 40.

RICHARD, F.J., SIRARD, M.A. (1996). Effects of follicular cells on oocyte maturation. I: Effects of follicular hemisections on bovine oocyte maturation in vitro. Biol. Reprod. 54: 16-21.

RIEGER, D., LOSKUTOFF, N.M. (1994). Changes in the metabolism of glucose, pyruvate, glutamine and glycine during maturation of cattle oocytes in vitro. $J$. Reprod. Fertil. 100: 257-262.

ROBERT, C., GAGNE, D., BOUSQUET, D., BARNES, F.L., SIRARD, M.A. (2001). Differential display and suppressive subtractive hybridization used to identify granulosa cell messenger rna associated with bovine oocyte developmental competence. Biol. Reprod. 64: 1812-1820.

RODGERS, R.J., IRVING RODGERS, H.F. (2002). Extracellular matrix of the bovine ovarian membrana granulosa. Mol. Cell. Endocrinol. 191: 57-64.

RUSSELL, D.L., SALUSTRI, A. (2006). Extracellular matrix of the cumulus-oocyte complex. Semin. Reprod. Med. 24: 217-227.

SALAMONE, D.F., ADAMS, G.P., MAPLETOFT, R.J. (1999). Changes in the cumulusoocyte complex of subordinate follicles relative to follicular wave status in cattle. Theriogenology. 52: 549-561.

SCARAMUZZI, R.J., BAIRD, D.T., CAMPBELL, B.K., DRIANCOURT, M.A., DUPONT, J., FORTUNE, J.E., GILCHRIST, R.B., MARTIN, G.B., MCNATTY, K.P., MCNEILLY, A.S., MONGET, P., MONNIAUX, D., VINOLES, C., WEBB, R. (2011). Regulation of folliculogenesis and the determination of ovulation rate in ruminants. Reprod. Fertil. Dev. 23: 444-467.

SIRARD, M.A., FLORMAN, H.M., LEIBFRIED-RUTLEDGE, M.L., BARNES, F.L., SIMS, M.L., FIRST, N.L. (1989). Timing of nuclear progression and protein synthesis necessary for meiotic maturation of bovine oocytes. Biol. Reprod. 40: 1257-1263.

SIRARD, M.A., PICARD, L., DERY, M., COENEN, K., BLONDIN, P. (1999). The time interval between $\mathrm{FSH}$ administration and ovarian aspiration influences the development of cattle oocytes. Theriogenology. 51: 699-708.

SU, Y.Q., SUGIURA, K., EPPIG, J.J. (2009). Mouse oocyte control of granulosa cell development and function: paracrine regulation of cumulus cell metabolism. Semin. Reprod. Med. 27: 32-42.

TAKAMI, M., PRESTON, S.L., TOYLOY, V.A., BEHRMAN, H.R. (1999). Antioxidants reversibly inhibit the spontaneous resumption of meiosis. Am. J. Physiol. 276: E684-688.

TAMURA, H., TAKASAKI, A., MIWA, I., TANIGUCHI, K., MAEKAWA, R., ASADA, H., TAKETANI, T., MATSUOKA, A., YAMAGATA, Y., SHIMAMURA, K., MORIOKA H., ISHIKAWA, H., REITER, R.J., SUGINO, N. (2008). Oxidative stress impairs oocyte quality and melatonin protects oocytes from free radical damage and improves fertilization rate. J. Pineal. Res. 44: 280-287.

TATONE, C., AMICARELLI, F., CARBONE, M.C., MONTELEONE, P., CASERTA, D. MARCI, R., ARTINI, P.G., PIOMBONI, P., FOCARELLI, R. (2008). Cellular and molecular aspects of ovarian follicle ageing. Hum. Reprod. Update. 14: 131-142.

TESARIK, J., MENDOZA, C. (1997). Direct non-genomic effects of follicular steroids on maturing human oocytes: oestrogen versus androgen antagonism. Hum. Reprod. Update. 3: 95-100.

WALSH, S.W., MEHTA, J.P., MCGETTIGAN, P.A., BROWNE, J.A., FORDE, N., ALIBRAHIM, R.M., MULLIGAN, F.J., LOFTUS, B., CROWE, M.A., MATTHEWS, D., DISKIN, M., MIHM, M., EVANS, A.C. (2012). Effect of the metabolic environment at key stages of follicle development in cattle: focus on steroid biosynthesis. Physiol. Genomics. 44: 504-517.

YEO, C.X., GILCHRIST, R.B., LANE, M. (2009). Disruption of bidirectional oocytecumulus paracrine signaling during in vitromaturation reduces subsequent mouse oocyte developmental competence. Biol. Reprod. 80: 1072-1080.

ZHENG, P., PATEL, B., MCMENAMIN, M., MORAN, E., PAPROCKI, A.M., KIHARA M., SCHRAMM, R.D., LATHAM, K.E. (2005). Effects of follicle size and oocyte maturation conditions on maternal messenger RNA regulation and gene expression in rhesus monkey oocytes and embryos. Biol. Reprod. 72: 890-897.

ZIELAK, A.E., FORDE, N., PARK, S.D., DOOHAN, F., COUSSENS, P.M., SMITH G.W., IRELAND, J.J., LONERGAN, P., EVANS, A.C. (2007). Identification of novel genes associated with dominant follicle development in cattle. Reprod. Fertil. Dev. 19: 967-975. 


\section{Further Related Reading, published previously in the Int. J. Dev. Biol.}

Unaltered imprinting establishment of key imprinted genes in mouse oocytes after in vitro follicle culture under variable folliclestimulating hormone exposure

Ellen Anckaert, Tom Adriaenssens, Sergio Romero, Sarah Dremier and Johan Smitz Int. J. Dev. Biol. (2009) 53: 541-548

Paracrine actions of oocytes in the mouse pre-ovulatory follicle A Salustri

Int. J. Dev. Biol. (2000) 44: 591-597

Age and gonadotropins control Ca2+-spike acquisition in mouse oocytes isolated from early preantral follicles

J E Gomes, A Pesty, A Gouveia-Oliveira, A J Cidadão, C E Plancha and B Lefèvre

Int. J. Dev. Biol. (1999) 43: 839-842

Developmental competence of immature pig oocytes under the influence of EGF, IGF-I, follicular fluid and gonadotropins during IVM-IVF processes

M J Illera, P L Lorenzo, J C Illera and R M Petters

Int. J. Dev. Biol. (1998) 42: 1169-1172

In vitro production of cattle embryos: review and Belgian results

P Mermillod, A Massip and F Dessy

Int. J. Dev. Biol. (1992) 36: 185-195

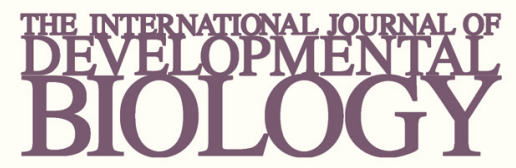

Volume 54 Nos. 6/7
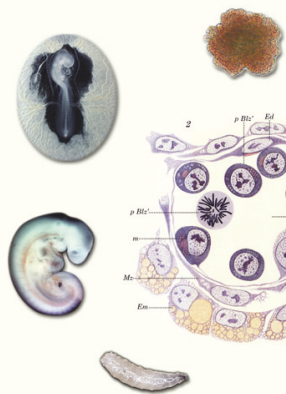

(2) (1)
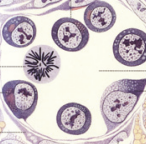

(3)

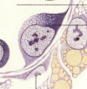

-

5 yr ISI Impact Factor $(2011)=2.959$

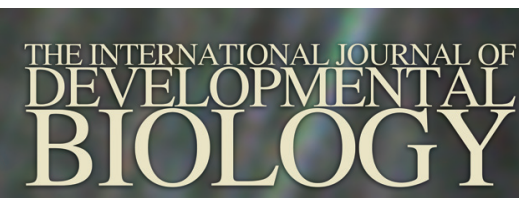

Volume 56 Nos. $1 / 2 / 3$

Special Issue

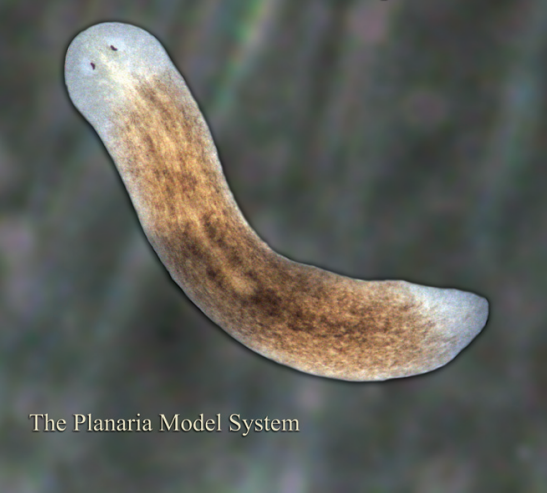

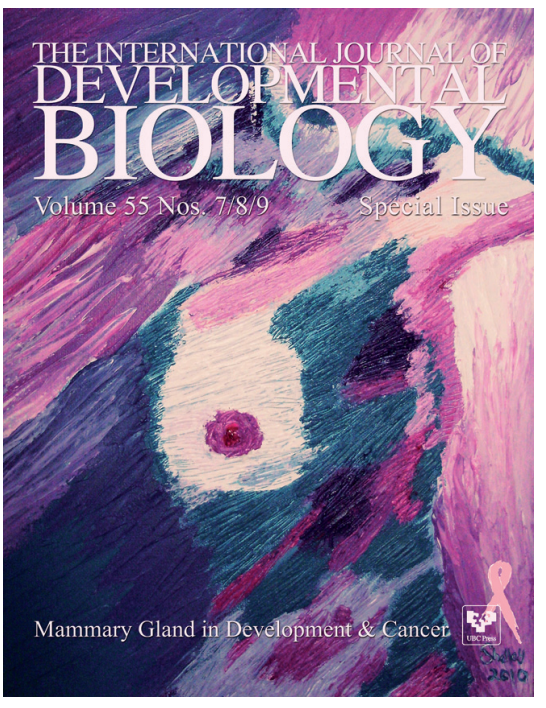

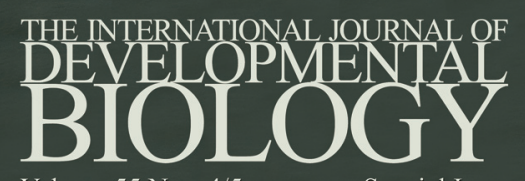

Volume 55 Nos. $4 / 5$

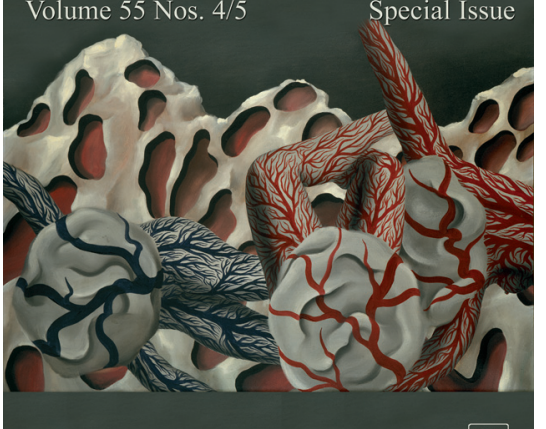

Angiogenesis in Development \& Cancer 